\title{
Integrating bioinformatics and epigenetics with Ayurveda-a possible contribution towards COVID-19 fight
}

\author{
Pooja Sabharwal1*, John Fagen², Rima Dada ${ }^{3}$, Ashok Sharma ${ }^{4}$, Chandra Shekher Kaushik ${ }^{5}$, \\ Ashutosh Chaturvedi ${ }^{6}$, Priyanka Bhardwaj ${ }^{7}$ \\ ${ }^{1}$ Department of Rachana Sharir, Chaudhary Brahm Prakash Ayurved Charak Sansthan, New Delhi, India \\ ${ }^{2}$ Health Research Institute, USA \\ ${ }^{3}$ Lab for Molecular Reproduction and Genetics, Department of Anatomy, All India Institute of Medical Sciences, New Delhi, India \\ ${ }^{4}$ Laboratory of Chromatin and Cancer Epigenetic, Department of Biochemistry, All India Institute of Medical Sciences, New Delhi, India \\ ${ }^{5}$ South Delhi Municipal Corporation, New Delhi, India \\ ${ }^{6}$ Department of Kayachikitsa, Institute of Medical Sciences, Banaras Hindu University, Varanasi, Uttar Pradesh, India \\ ${ }^{7}$ Department of Rachana Sharir, Chaudhary Brahm Prakash Ayurved Charak Sansthan, New Delhi, India
}

\section{KEY WORDS}

\section{Ayurveda}

COVID-19

Ayurinformatics

Epigenetics

Infectious diseases

Antiviral drugs

\begin{abstract}
Background: The entire world is struggling from the COVID-19 pandemics. Scientific community all around the world have been looking for any possible measure to fight against this dreadful disease. Ayurveda, the traditional Indian system of medicine, has immense potential to contribute towards this pandemic both in prevention and management. But Ayurveda fraternity has the challenge to explain the available possible measures in contemporary language. The science of bioinformatics \& epigenetics has provided possibility for scientific \& contemporary explanation of Ayurvedic interventions.

Summary: This paper is an attempt to discuss about various possibilities and challenges from Ayurveda perspective against COVID-19 in the purview of Ayurinformatics and Epigenetics.
\end{abstract}

\begin{abstract}
Key messages
Ayurinformatics have been applied successfully earlier to infectious diseases \& scientists have screened many phytochemicals from medicinal plants in silico against covid 19. Further with the advance knowledge of epigenetics, intervention of Ayurveda on different expressed variants of coronavirus with intervention of screened phytochemicals discovered in silico with the knowledge of science of ayurinformatics will certainly contribute towards the fight with covid 19.
\end{abstract}

doi: $10.38205 /$ imcr.010239

\author{
*Corresponding Author: \\ Pooja Sabharwal, MD, PhD \\ Chaudhary Brahm Prakash Ayurved \\ Charak Sansthan, New Delhi, India \\ Contact no: 9650190893 \\ E-mail: drpoojasabharwal@gmail.com
}

\section{Introduction}

In the recent past, there is a history of various infectious diseases worldwide. At this juncture, when the entire world is struggling to find the possible solution against the dreadful viral disease COVID-19 (1). Ayurveda, the traditional Indian system of medicine, has various evidence for the management of infectious disease (2). It is believed that such kind of contagious diseases is only manageable by contemporary science which is a partial truth. Ayurveda science has a very well explanation of epidemics and communicable diseases $(3,4)$. In classical texts of Ayurveda, microorganisms and their role in disease have been described. As per Ayurveda text causative factors for epidemics which commonly affect particular locality, causing threatened death are vitiated air, water, soil, and season $(5,6)$. Surprisingly a recent study has shown a link between pollution and the intensity of the COVID-19 disease. It is further explained in Ayurveda literature that the person having a different constitution, diet, physical strength, mental conditions, age, get afflicted by epidemic disease. Thus jeopardize the health of the nation, because the factors which are familiar to all inhabitants are air, water, place and season (7).

In the classical literature of Ayurveda, it is described the importance of the body's immunity over the infective organisms. It is explained that Bija (seeds) soaked in Bhoomi (land) flourishes only in the right time that is the atmosphere, and Doshas vitiates means microorganism responsible for denying Doshas. Dhatus if Dhatus' Bala means immunity depleted only then disease manifestation will occur (8). So, it is a clear explanation about the body's specific and nonspecific immunity which plays a major role in the manifestation of any disease including epidemic. While describing about communicable diseases, their prevention by immunity boosting drugs, description about antiviral drugs is also available in classical literature of Ayurveda. In this present era, the dire need is explanation of the modalities described in Ayurveda in communicable diseases like in COVID-19 in purview of contemporary science. The science of Ayurinformatics and epigenetics has 
provided that opportunity for possible scientific explanation of those interventions.

\section{Evidence of Antiviral drugs in Ayurveda}

The concept of the epidemic and infectious diseases is very well described in the classical literature of Ayurveda. The remedies to combat outbreaks are also available in Ayurveda. Description about medicinal plants with their antiviral properties is available in Ayurveda texts. There are various studies to evident the potential of Ayurveda drugs as antiviral property like-Tulsi, Hardira, Guduchi, Rasona etc (9-28).

\section{Challenges}

Ayurveda has often been labeled a pseudoscience due to lack of understanding of its fundamental principles, which are difficult to understand from the perspective of mainstream medical terminology. Furthermore, the new parameter and research language are entirely different as an understanding of the human body is different from the Ayurvedic perspective. Ayurveda considers the whole body and mind is the root cause for any problem as different tissues or systems in the collection aren't separate entities but interact with each other. Further, in the case of infectious diseases, the appearance of symptoms and morbidity are variable in different race and gender.

\section{Integrated approach \& Research-a Possible solution}

Although till date, there are no clinical evidence-based integrative prevention or treatment strategies for COVID-19 infection (29). Despite this, there is a worldwide interest in integrative management of this dreadful disease. Chinese traditional medicines have been used in combination with allopathic treatments for symptomatic alleviation in COVID-19 cases (30). In China, different Traditional Chinese Medicine (TCM) methods have already been tested in the recent crisis, including decoctions of qingfeipaidu (QPD), gancaoganjiang, and sheganmahuang, and qingfeitouxiefuzheng recipes which were confirmed to be an effective treatment for COVID-19. Additionally, physical exercises of the TCM, Baduanjin exercise and Tai Chi helped improving immunity and cardiopulmonary function of COVID-19 patients in the Fangcang shelter (31-33). Ayurveda, one of the world's renowned Indian traditional medicine, mentions several immunity-boosting therapeutics. It is known that COVID-19 affects individuals with weak immunity more severely. Therefore, enhancing immunity is one of the way doctors across the globe have been using for treating COVID-19 cases. Considering the same Ministry of AYUSH (MOA) has recommended immunity enhancing herbs and issued guidelines. MOA has invited integrated research proposals for any possible solution from all physicians and team of scientists pan India. A task force is working along with ICMR, CSIR and DST. Integrated approach is the best option to combat this dreadful viral disease. An integrated approach may not only enhance immunity but also maybe a useful adjunct in the management of this disease and prevent its sequel and complications.

\section{Research possibilities in the purview of Ayurinformatics and epigenetics}

It is interesting to note that the concepts described centuries back are very much relevant to the contemporary era and their significance cannot be neglected. The modalities described in Ayurveda for the prevention and management of infectious diseases can be applied at individual and community level that bears considerable public health importance. So, understanding of fundamentals with the relevant knowledge of modern concepts, the possible future research doors in the purview of Ayurinformatics and epigenetics is described now.

\section{Ayurinformatics}

Ayurinformatics is a science dealing with the application of bioinformatics to the Ayurvedic medication. Bioinformatics is a relation between Biology and Computers. Bioinformatics is the field of science in which biology, computer science, and information technology merge into a single discipline. Bioinformatics is the science of managing and analyzing biological data using advanced computing techniques.

Ayurinformatics have been applied earlier to infectious diseases and cancer. With the advancement of new technologies, the molecular biology of COVID-19 development is becoming clear to us. Many scientists have shown interest in targeting the proteins involved in COVID-19 to develop the vaccine. If the conventional drug designing technologies and bioinformatics are applied to the traditional Ayurveda, then it will prove to be a boon to the medical science (34). The most powerful and useful techniques to discover novel ligands for receptors of known structure is in-silico molecular docking that plays a significant role in structure-based drug designing (35).

In one of the study, Ayurvedic remedy for Ebola hemorrhagic fever (36) was established by homology modelling within-silico docking, and medication for Alzheimer's disease (37) was previously reported. In another study, an in-silico molecular docking was done to check the effectiveness of active compounds from ginger for their binding capacity to NADH oxidoreductase enzyme as ligands. Active compounds of ginger (Zingiberoficinale Roscoe) gingerol, paradol, shogaol and zingerone were chosen as ginger is known to have anticancer properties.

A 3D model of the human NADH dehydrogenase was developed in-silico. Further, it was docked with gingerol, paradol, shogaol and zingerone (38). Successful docking was observed in all of them. Two compounds, namely 6-gingerol and 10-gingerol, formed covalent bonds with the enzyme proving that they are the most potent for drug development among the active components of ginger. In another study where the translation pathway of fumaratehydratase (FH) mutation gene was blocked by RNA technique. By which established an Ayurvedic remedy for uterine fibroids. In this study, FH precursor (mutation) protein was taken. Homology modelling 
studies modelled 3D structure of FH protein. Active components of few Ayurvedic herbs like Aloe vera, Commiphoramukul, Asparagus racemose and Saracaindica were selected, combined \& docked with FH mutation protein. It was proved that after this docking that the combination is effective in curing uterine fibroids. The UniProt database (accession number P07954) was used to retrieve the FH mutation protein; later homology modelling was done using modeller 9v7 software using templates (homologous proteins in the RCSB's PDB database). The chemical structure of all active components is drawn using ACD/Chemsketch software (38).

\section{Ayurinformatics and COVID-19}

As there are no targeted therapeutics and interventional options are very limited. To rapidly discover lead compounds for clinical use, the scientists from China initiated a program of combined structure-assisted drug design, later virtual drug screening and high-throughput screening. It was done to identify new drug targeting the COVID-19 virus main protease $\left(\mathrm{M}^{\mathrm{pro}}\right)$ (39-40). Scientists have determined the crystal structure of COVID-19 virus $\mathrm{M}^{\text {pro }}$ and identified a mechanism-based inhibitor, N3 by computer-aided drug design. Scientists assayed over 10,000 compounds including approved drugs, through a combination of structure-based virtual and high-throughput screening as inhibitors of $\mathrm{M}^{\text {pro }}$. Out of these six compounds inhibited $\mathrm{M}^{\text {pro }}$, These results have proven the efficacy of this screening strategy, which can lead to the rapid discovery of drug leads with clinical potential in response to coronavirus.

Similarly, scientists are trying in silico docking of Ayurvedic phytochemicals against this virus (41-43). In the recent study, scientists have screened almost 1000 phytochemicals from more than 100 medicinal plants, in-silico. Scientists have tested for phytochemicals finding affinities to COVID-19 essential proteins and host protein interactions. It was discovered that natural photochemical in Mulethi, Curcumin, Ashwagandha, Giloy and Tulsi indeed have potentials to combat COVID-19 and its pathogenicity (43).

Some studies have found that that Ayurvedic drugs like Ashwagandha, Guduchi and Mulethi might be potent against COVID-19. In some of the reviews, COVID-19 has been shown to engage the host cell ACE2 through its spike protein receptorbinding domain (RBD). Scientists have discovered that W. somnifera compound, Withanone, docking proved in the binding interface of AEC2-RBD complex. It has been observed that Withanone significantly decreased electrostatic component of binding free energies of ACE2-RBD complex. Two salt bridges were also identified at the interface; incorporation of Withanone destabilized these salt bridges and decreased their occupancies. Theories have been postulated that such an interruption of electrostatic interactions between the RBD and ACE2 would block or weaken COVID-19 entry and its subsequent infectivity. It shows that natural phytochemicals could well be the viable options for controlling COVID-19 entry into host cells, and W. somnifera may be the first choice of herbs in these directions to curb the COVID-19 infectivity (44).
Similarly, it was found that a phytochemical Tinocordiside from Giloy (Tinosporacordifolia), also binds in the ACE2-RBD complex with strong binding affinities. Tinosporacordifolia has also is shown to possess HIV-protease inhibitory activity. (Willd.) (45).

In another study, it has been shown that Withaferin $\mathrm{A}$ (WA), an active constituent of Withaniasomnifera, an ayurvedic herb has demonstrated a strong binding affinity with Neuraminidase (NA). NA is a membrane surface antigen that facilitates the release of influenza viruses from the host cells after replication. Several anti-influenza drugs such as zanamivir bound with the active site of NA and stopped the viral release the from host cells. After such kind of successful reports, there is a lot of interest among the scientific community for alternative drug candidates, preferably from plant source due to their known benefits such as less or no side effects, availability, and low cost. Studies have shown that it has the potential to attenuate the NA of H1N1 influenza. In silico docking and simulation results predicted high binding affinity of the WA toward NA and revealed several interesting molecular interactions with the residues which are catalytically important during molecular dynamic simulations (46). So, by taking the knowledge from bioinformatics and merging it with Ayurveda (Ayurinformatics) can lead to the rapid discovery of Ayurvedic formulations against COVID-19.

\section{Epigenetics and COVID-19}

Epigenetics is the new field of discussion among researchers. Scientists are experimenting the research on biochemical modifications beyond the DNA strand to lead to massive progress in the understanding of the regulation of gene activity shortly. Thomas Lengauer and Christoph Bock from the Max Planck Institute for Informatics in Saarbrücken have demonstrated by their work that how epigenetics research is applicable in medical application. DNA methylation and histone modification play a central role in gene regulation: small hydrocarbon attachments thus decide whether a gene is "active" or "silenced", namely whether it can be transcribed or not.

In the case of viral infections, interferons and innate immune responses are dependent upon extensive epigenetic regulation. They are influenced by specific epigenetic marks, and the manipulation of DNA methylases and histone modification enzymes, chromatin re-modelling complexes. It has been studied that theseviruses evolve specific mechanisms which create hurdles and antagonize these regulatory programs (46).

Marazzi et al. have demonstrated that the highly pathogenic H3N2 influenza-A virus inhibits the initiation of the host innate immune response in part by interfering with the epigenetic control of gene expression. Similarly, it has been reported in studies that corona viruses induce changes in the basal state of host chromatin. In another study, it has been seen that the infection of Calu3 cells (a human airway epithelial cell line) with the tested respiratory viruses resulted 
in different virus-specific ISG (interferon-stimulated gene) expression marks. The H5N1 avian influenza A (HPIA) virus showed a rapid manipulation of ISG. In contrast to the H1N1 strain showed no ISG modulation. It has been observed in case of SARS-CoV that showed a strong induction of ISG effectors, but the response was significantly delayed with peak expression at 24 to $48 \mathrm{~h}$ post-infection. On the other hand, MERSCoV showed delayed ISG production with effects visible at 18-hour post-infection (HPI), with significant inhibition of expression of specific ISG subsets. Overall, the viral manipulation of the host antiviral IFN response results in successful virus infection and viral replication, defining a viral antagonistic approach, which may be a mechanism to interfere with the host's innate immune response (47-56).

\section{Integrating Epigenetics, Bioinformatics and Ayurveda}

As Ayurveda is a rich science with potential antiviral drugs, drugs for enhancing our immunity to prevent as well as manage the disease, but it are equally important to understand the mechanism in the purview of contemporary science. With the advance knowledge of bioinformatics and epigenetics, it is possible to explain the ISG expression. On the other hand, the scientists have screened many phytochemicals from medicinal plants, in-silico. In various studies, scientists have looked for their binding affinities to COVID-19 essential proteins and host protein interactions with the knowledge of the science of epigenetics and bioinformatics.

This pandemic has jolted the minds of researchers, scientists and policy makers throughout the world. Brain storming among various task forces, working groups team of researchers is going on to find the possible solution for the same. Thus by taking the knowledge of various successful studies done in the area of antiviral diseases which have been mentioned in the above review and further understanding from Ayurinformatics and Epigenetics point of view, it is possible for intervention of Ayurvedic formulations, diet and even non-pharmacological interventions for successful molecular docking against differently expressed variants of corona virus. Rigorous research in this direction may give arise to some solutions to address the psychological trauma in society \& find an effective preventive medication for COVID 19.

\section{Conclusion}

A collaborative, integrated approach with Ayurveda and contemporary science is a possible solution and contribution against this dreadful virus. The intervention of Ayurveda on different expressed variants of coronavirus with the knowledge of epigenetics and further by silico docking with photochemical. Applying the knowledge of bioinformatics will lead to the rapid invention of Ayurvedic drugs against COVID-19.

\section{Acknowledgments}

I would like to acknowledge the scientific work done by Patanjali trust Haridwar, India \& constant support given by
Dr. Deep Narayan Pandey \& Dr Ajit kolatkar \& Dr Arvind Aggarwal during this work.

\section{Authorship contributions}

PS: Contributed toward concepts, design, definition of intellectual content, literature search, experimental studies, data acquisition, manuscript preparation, manuscript editing, manuscript review, and agrees to act at guarantor.

JF: Contribute toward concepts, design, definition of intellectual content, experimental studies, data acquisition, statistical analysis, manuscript editing, and manuscript review.

RD: Contributed toward concepts, design, definition of intellectual content, literature search, experimental studies, data acquisition, statistical analysis, manuscript preparation, manuscript editing, manuscript review.

AS: Contributed toward concepts, design, definition of intellectual content, literature search, experimental studies, data acquisition, data analysis, statistical analysis, manuscript preparation, manuscript editing, manuscript review.

CSK: Contributed toward concepts, design, definition of intellectual content, literature search, experimental studies, data acquisition, data analysis, statistical analysis, manuscript preparation, manuscript editing, and manuscript review.

AC and PB: Contributed toward concepts, design, definition of intellectual content, literature search, experimental studides, data acquisition, data analysis, and manuscript review.

\section{Funding statements}

The authors received no financial support for the research, authorship, and/or publication of this article.

\section{Source of funding}

Nil

\section{Conflict of interest}

The authors do not have any conflicts of interest.

Received Date: 02-07-20; Revised Date: 09-07-20

Accepted Date: $11-07-20$

\section{References}

1. Hui DS, Azhar EI, Madani TA, Ntoumi F, Kock R, Dar O, et al. The continuing 2019-nCoV epidemic threat of novel coronaviruses to global healthThe latest 2019 novel coronavirus outbreak in Wuhan, China. International Journal of Infectious Diseases. 2020;91:264-6.

2. "WHO Director-General's opening remarks at the media briefing on COVID-19". World Health Organization (WHO) (Press release). 11 March 2020. Retrieved 12 March 2020.

3. Gavande S, Mane J. Role of Ayurved in Epidemic Diseases Due to World War-A Critical Review. International Journal of Science and Research. 2014;5(2).

4. Shukla N. Ayurvedic Approach to Communicable Disease - An Overview. Journal of Community Medicine \& Health Education. 2012;01(S1).

5. Samal J. Fundamental tenets of epidemiology in Ayurveda and their contemporary relevance. Indian Journal of Health Sciences. 2016;9(1):20.

6. Bano N, Ahmed A, Tanveer M, Khan Gm, Ansari MT. Pharmacological Evaluation of Ocimum sanctum. J Bioequiv Availab. 2017;9:387-392 
7. Samal J. Fundamental tenets of epidemiology in Ayurveda and their contemporary relevance. Indian Journal of Health Sciences. 2016;9(1):20.

8. Bhushan Patwardhan, Preeti Chavan-Gautam, Manish Gautam, Girish Tillu, Arvind Chopra, Sunil Gairola et al. Ayurvedarasayana in prophylaxis of COVID-19. Current Science, 2020

9. J Cinatl, B Morgenstern, G Bauer, P Chandra, H Rabenau, H Doerr. Glycyrrhizin, an active component of liquorice roots, and replication of SARS-associated coronavirus. The Lancet. 2003;361(9374): 2045-2046.

10. Hoever G, Baltina L, Michaelis M, Kondratenko R, Baltina L, Tolstikov G et al. Antiviral Activity of Glycyrrhizic Acid Derivatives against SARSCoronavirus. Journal of Medicinal Chemistry. 2005;48(4):1256-1259.

11. Mounce B, Cesaro T, Carrau L, Vallet T, Vignuzzi M. Curcumin inhibits Zika and chikungunya virus infection by inhibiting cell binding. Antiviral Research. 2017;142:148-157.

12. Lin L, Hsu W, Lin C. Antiviral Natural Products and Herbal Medicines. Journal of Traditional and Complementary Medicine. 2014;4(1):24-35.

13. Atilla Çifci, Cüneyt Tayman, Halil İbrahim, Yakut, Halit Halil, Esra Çakır, Ufuk Çakır, Salih Aydemir. Ginger (Zingiberofficinale) prevents severe damage to the lungs due to hyperoxia and inflammation. Turkish journal of medical sciences. 2018;48(4).

14. Ahmad, A, M. R. Javed, A. Q. Rao and T. Husnain. "Designing and screening of universal drug from neem (Azadirachtaindica) and standard drug chemicals against influenza virus nucleoprotein." BMC Complementary and Alternative Medicine; 2016;16(1).

15. Rani P, Sharma K, Kumar K. Probable mode of action of sanjivanivati - a critical review. Int J Health Sci Res. 2018;8(8):295-307.

16. Singh A, Agrawal K, Dadhich OP. Pharmacodynamics of Shatyadichurna in the management of Tamaka Shwasa. The Pharma Innovation Journal 2018;7(6):516-518.

17. Ghoke, S.S. "Evaluation of Antiviral Activity of Ocimum sanctum and Acaica Arabica leaves extracts against H9N2 virus using embryonated chicken egg model." BMC complementary and alternative medicine 2018;174.

18. Usha Patil. Studies on antiviral activity of tulsi (ocimum sanctum) crude exractson selected viruses of veterinary importance. International Journal of Ayurveda And Pharma Research. 2018;6(4):17-21.

19. Benencia, F., and M. C. Courreges. In vitro and in vivo activity of eugenol on human herpes virus. Phytotherapy Research: An International Journal Devoted To Pharmacological And Toxicological Evaluation Of Natural Product Derivatives; 2000:495-500.

20. Yucharoen, Raenu, Songyot Anuchapreeda, and Yingmanee Tragoolpua. Antiherpes simplex virus activity of extracts from culinary herbs Ofocimum sanctum l, Ocimumbasilicum l. and Ocimumamericanum $\mathrm{l}$. African Journal of Biotechnology 10.5 (2011):860-866.

21. Goel, Anjana. Invitro antiviral potential of ocimum sanctum leaves extract against new castle disease virus of poultry. International Journal of Microbiology And Immunology Research. 2013;51-55.

22. Kumar, Amit. Ocimum sanctum (Tulsi): a miracle herb and boon to medical science- A Review. Int J Argon Plant Prod. 2013;4(7):1580-9.

23. Badam L. S. P. Joshi, and S. S. Bedekar. In vitro antiviral activity of neem (Azadirachtaindica A. Juss) leaf extract against group B coxsackieviruses." The Journal of Communicable Diseases 1999;31(2):79-90.

24. Trivedi A, Fatima N, Husain I, Misra A. An Update on Therapeutic Potential of Neem and Its Active Constituents: A Panacea For All Diseases. Era J. Med. Res. 2019;6(1):1-8

25. Imrana, Ishrat, et al. Invitro evaluation of Antiviral activity of leaf extracts of Azadirachtaindica, Moringaoleifera and Morus alba against the foot and mouth disease virus on BHK-21 cell line. Scienceasia 2016; 42(6): 392-396.

26. Parida M. M. Inhibitory potential of neem (Azadirachtaindica) leaves on dengue virus type-2 replication. Journal of Ethnopharmacology 2002; 79(2):273-278.

27. Dhama K, Sachan S, Khandia R, Munjal A, Iqbal HMN, LAtheef SK, et al. Medicinal and Beneficial Health Applications of Tinosporacordifolia
(Guduchi): A Miraculous herb Countering Various Diseases/ Disorders and its Immunomodulatory effects. 2017;10(2):96-111.

28. Liang-Tzung L, Wen-Chang H, Chung-Chin, L. Antiviral Natural Products and Herbal Medicines. Journal of Traditional and Complementary Medicine, 2014;4(1):24-35

29. Alschuler L, Weil A, Horwitz R, Stamets P, Chiasson A, Crocker R et al. Integrative considerations during the COVID-19 pandemic. EXPLORE. 2020.

30. Ling C. Traditional Chinese medicine is a resource for drug discovery against 2019 novel coronavirus (SARS-CoV-2). Journal of Integrative Medicine. 2020;18(2):87-88.

31. Ren J, Zhang A, Wang X. Traditional Chinese medicine for COVID-19 treatment. Pharmacological Research. 2020;155:104743.

32. Yang Y, Islam M, Wang J, Li Y, Chen X. Traditional Chinese Medicine in the Treatment of Patients Infected with 2019-New Coronavirus (SARSCoV-2): A Review and Perspective. International Journal of Biological Sciences. 2020;16(10):1708-1717.

33. Li Ni. Combination of western medicine and Chinese traditional patent medicine in treating a family case of COVID-19 in Wuhan. Frontiers of Medicine. 2020.

34. Tripathi A, Srivastava SK. Ecofriendly treatment of azo dyes: biodecolorization using bacterial strains. International Journal of Bioscience, Biochemistry and Bioinformatics. 2011;1(1):37.

35. Brooijmans N, Kuntz ID. Molecular recognition and docking algorithms. Annual review of biophysics and biomolecular structure. 2003;32(1):335-73.

36. Bagchi A, Gopakumar R. Galilean conformal algebras and AdS/CFT. Journal of High Energy Physics. 2009;(07):037.

37. Timmerman R, Paulus R, Galvin J, Michalski J, Straube W, Bradley J, Fakiris A, Bezjak A, Videtic G, Johnstone D, Fowler J. Stereotactic body radiation therapy for inoperable early stage lung cancer. Jama. 2010;303(11):1070-6

38. Preenon Bagchi, Nikita Sinha, Ajit Kar, and Mahesh. M Ayur-Informatics: Establishing an Ayurvedic Remedy for Bronchial Carcinoma IJBBB 2011 1(1):41-46

39. Zhenming Jin, Xiaoyu Du, et al. Structure of Mpro from COVID-19 virus and discovery of its inhibitors. Natureresearch. 2020.

40. Chandel V, Raj S, Rathi B, Kumar D. In Silico Identification of Potent COVID-19 Main Protease Inhibitors from FDA Approved Antiviral Compounds and Active Phytochemicals through Molecular Docking: A Drug Repurposing Approach. 2020.

41. Ramaiah M, Vishwakarma R, Shaanker R. Molecular Docking analysis of selected natural products from plants for inhibition of SARS-CoV-2 main protease. Current science. 2020;118(7):1087-1092.

42. In silico Identification of Potent COVID-19 Main Protease Inhibitors from FDA approved Antiviral Compounds and Active Phytochemicals through Molecular Docking: A Drug Repurposing Approach Vaishali Chandel1, Sibi Raj1, Brijesh Rathi2, Dhruv Kumar1,*

43. Balakrishna A, Pokhrel S, Singh J, Varshney A. Withanone from Withania somnifera may inhibit novel coronavirus (covid-19) entry by disrupting interactions between viral s-protein receptor binding domain and host ACE-2 receptor. Virology. 2020

44. Anuya A, Anil R, Abhay SC. Evaluation of Ocimum sanctum and Tinosporacordifolia as Probable HIV-Protease Inhibitors. International Journal of Pharmaceutical Sciences Review and Research. 2014;25(1): 315-318.

45. Zhi Cai, Guoyin Zhang, Bin Tang, Yan Liu, Xiaojing Fu, Xuejin Zhang. Promising Anti-influenza Properties of Active Constituent of Withaniasomnifera Ayurvedic Herb in Targeting Neuraminidase of H1N1 Influenza: Computational Study. Cell Biochemistry and Biophysics. 2015;72: 727-739.

46. Obata Y, Furusawa Y, Hase K. Epigenetic modifications of the immune system in health and disease. Immunol. Cell Biol. 2015;93:226-232.

47. Busslinger M., Tarakhovsky A. Epigenetic control of immunity. Cold Spring Harb. Perspect. Biol. 2014;6 
48. Collins FS, Morgan M, Patrinos A. The Human Genome Project: Lessons from large-scale biology. Science. 2003;300:286-290.

49. Rivera CM, Ren B. Mapping human epigenomes. Cell. 2013;155:39-55.

50. Schuster SC. Next-generation sequencing transforms today's biology. Nat. Methods. 2008;5:16-18.

51. Rakyan VK, Down TA, Balding DJ, Beck S. Epigenome-wide association studies for common human diseases. Nat. Rev. Genet. 2011;12:529-541.

52. Birney E, Smith GD, Greally JM. Epigenome-wide Association Studies and the Interpretation of Disease -Omics. PLoS Genet. 2016;12:e1006105.

53. Consortium EP, Birney E, Stamatoyannopoulos JA, Dutta A, Guigo R, Gingeras TR, Margulies EH, Weng Z, Snyder M, Dermitzakis ET, Thurman
RE, Kuehn MS, Taylor CM, Neph S, Koch CM, Asthana S, Malhotra A, Adzhubei I, Greenbaum JA, etal.: Identification and analysis of functional elements in $1 \%$ of the human genome by the ENCODE pilot project. Nature 2007;447:799-816.

54. Schäfer A, Baric RS. Epigenetic landscape during coronavirus infection. Pathogens. 2017 Mar;6(1):8.

55. Sardar R, Satish D, Birla S, Gupta D. Comparative analyses of SAR-CoV2 genomes from different geographical locations and other coronavirus family genomes reveals unique features potentially consequential to host-virus interaction and pathogenesis. bio Rxiv. 2020 Jan 1. 